\title{
REFLEXIONES SOBRE EL HOLOCAUSTO A PARTIR DE LITERATURA
}

\author{
Reflections on the Holocaust from Literature \\ Martina Cociña CholakY ${ }^{1}$ \\ Universidad de O’Higgins, Chile \\ martinacoci@gmail.com
}

\section{Resumen}

A partir del examen de obras sobre el holocausto se reflexiona sobre su singularidad, sus implicaciones y consecuencias, reafirmando la necesidad de instaurar una ética contra el olvido. Ciertos textos logran testimoniar lo inconcebible, de ahí que se recurra a estos para aprehender las dimensiones de lo acontecido. La literatura tiene una función esencial en la tarea de la memoria pues, mediante la narración de historias, posibilita conocer cómo se organizó el régimen nazi, cuáles fueron las bases en que se asentó, cómo operó en sus ejecutores y cómo incidió en quienes lo padecieron; asimismo permite debatir acerca de la modernidad, el sufrimiento, la indiferencia y el mal. Este artículo es una invitación a confrontar críticamente el pasado reciente a partir de novelas que recogen testimonios que dan cuenta del universo de los campos de concentración y exterminio nazi.

Palabras clave: holocausto, literatura, nazismo, memoria, mal.

\section{Abstract}

From the examination of works on the holocaust, it reflects on its uniqueness, its implications and consequences, reaffirming the need to establish an ethic against

1 Doctora en Derecho y Ciencia Política de la Universidad de Barcelona, Máster de Criminología, Política Criminal y Sociología Jurídico Penal de la Universidad de Barcelona y Abogada de la Universidad de Chile.

DOI: $10.26754 /$ ojs_studium/stud.2019254268 
forgetting. Certain texts manage to bear witness to the inconceivable, which is why they are repeated to apprehend the dimensions of what happened. Literature has an essential function in the task of memory, because through the narration of stories, it allows to know how it was organized the Nazi regime, were the bases on which it was established, how they operated on its executors and how it affected those who suffer, they can allow to debate about of Modernity, suffering, indifference and Evil. This paper is an invitation to critically confront the recent past from novels that collect testimonies that account for the universe of the Nazi concentration and extermination camps.

Key words: holocaust, literature, nazism, memory, evil.

\section{INTRODUCCIÓN}

Holocausto proviene del griego bolokauston, significa reses quemadas como sacrificio en honor a Dios. Al ser un término que designa una especie de martirio judío (Hoffmann, 2011), los judíos consideran que es un eufemismo inaceptable, por lo que prefieren Shoah, una palabra hebrea sin connotaciones religiosas que hace referencia a devastación o desolación, un vocablo más ajustado a la realidad que se extendió a partir del documental homónimo de Lanzmann. También se ha utilizado 'Solución Final', Auschwitz o Lager para denominar el genocidio en proporciones industriales perpetrado en la Segunda Guerra Mundial. Este artículo emplea en su título el término más conocido universalmente; y en el texto, para evitar la reiteración, se usan dichas palabras indistintamente.

El holocausto es uno de los acontecimientos más estudiados. Existen innumerables testimonios que dan cuenta de lo que se vivió en los campos de concentración. Más que profundizar en temáticas analizadas profusamente, este artículo pretende, a través de relatos, reflexionar sobre cómo esta ideología se fue construyendo y desarrollando; así, se persigue debatir sobre la responsabilidad, la culpa, la conciencia y la ética. Para esta tarea la literatura constituye una valiosa herramienta ya que mediante historias particulares permite deliberar y conocer las estrategias usadas para el exterminio sistemático de millones de personas. Como afirma Hofmann (2011: 22), «la articulación del sufrimiento como la memoria del horror son imprescindibles, y de que la literatura es un medio fundamental de expresión de la memoria». Precisamente, «en un mundo donde se han borrado de manera tan evidente las fronteras entre civilización y barbarie, la pregunta por la cultura, y específicamente por la literatura, se vuelve urgente». (López, 2009:213) 
La reflexión se hará a partir de una obra que describe magníficamente lo que conllevó el nazismo, Las Benévolas, una novela de ficción histórica que mediante el testimonio de un culto oficial de las SS recoge los horrores de la Segunda Guerra Mundial. Max Aue, narrador y protagonista, recuerda a la muerte en una épica infernal caracterizada por la burocracia, por la política del Bien y el Mal y el inevitable horror presente en los Lager. Su autor, Jonathan Littell, mediante los vericuetos en que transcurre la personalidad de este agente, logra dar cuenta de los cimientos del régimen, su funcionamiento y aquello que le dio continuidad; ello le permite adentrarse en la lógica imperante, en los dilemas morales que afligían a algunos ejecutores, en el conocimiento de por qué esta ideología cobró fuerza y cómo se organizó el terror de Estado. A través de la psicología de Aue se muestra la violencia asesina acorde al mundo globalizado, donde lo civil ya no existe y se ha configurado una guerra total. Las Benévolas es un recuento histórico de la experiencia del terror, por eso permite debatir cómo el mundo civilizado se desbarató, cómo fue ejecutado ese plan masivo de exterminio, cómo la locura y la razón se conjugaron en una ideología que tenía una racionalidad instrumental, cómo la cultura no alcanza para detener el horror. En síntesis, es una obra que permite reconocer la vulnerabilidad que nos aqueja como sociedad. Por eso su importancia, porque nos recuerda que los ejecutores eran personas, igual que nosotros o, por lo menos, reconocibles en su humanidad.

Existen tres maneras de aproximarse al holocausto: histórica, biográfica y ficcional. Mientras la primera mirada atiende a los hechos del pasado y da a conocer lo acontecido basándose en sucesos históricos, la visión biográfica - a partir de testimonios de sobrevivientes - expone lo que fue la experiencia de quienes vivieron la maquinaria nazi; la tercera perspectiva, la ficcional, es utilizada por los denominados 'escritores de tercera generación’ (Aarons, 2016) que, por regla general, son judíos que no han vivido el universo concentracionario (Rousset, 2018). Como nuestra reflexión se realiza sobre una novela del escritor franconorteamericano Littell - que no experimentó la Shoab, sino que creció con esta historia por su familia de origen judío-, se enmarca en esta última aproximación. Contextualizado lo anterior, la relación entre memoria y testimonio cobra más sentido, en la medida que permite encajarla dentro de los autores que, a pesar de no vivir el holocausto, le dan voz al mismo, con la subsecuente dificultad de darle continuidad pues, como observa Aarons (2016: XVI), la tercera generación sugiere una «cadena continua necesariamente complicada en la transferencia de memoria de una generación a la siguiente y en un contexto por las interrupciones afectivas de esa continuidad»; esta ge- 
neración no sólo tiene una distancia temporal con el exterminio, sino una distancia discursiva de las historias contadas, lo que dificulta la reconstrucción de la memoria. Por eso, la tercera generación se encuentra en posición de ser simultáneamente remota y también conscientemente conectada a la memoria de Auschwitz (Aarons, 2016). De ahí la dificultad de representación en las narrativas contemporáneas de la transmisión del holocausto, a diferencia de los supervivientes que, al experimentarlo en primera persona, posibilitan una transferencia activa de la memoria; en este sentido, con la muerte de la primera generación se producirá una pérdida irrecuperable de la memoria, en tanto marcará el final del testimonio directo.

Si bien los intentos generacionales de descifrar el exterminio se fundan en la urgencia ética de derrotar la amnesia y representar el trauma, persiste la interrogante ¿qué retórica posibilita la identificación con personas que no han conocido o conocido muy escasamente? y ¿cómo se observa la Shoab desde una perspectiva contemporánea? Tal como apuntan Aarons y Berger (2017), la representación del Lager es una cuestión compleja, pues no sólo se vincula con la transmisión intergeneracional y continua del trauma, sino también con la identidad cultural judía, la memoria heredada, las tensiones psicológicas, los problemas de dislocación y con el futuro de la memoria.

Atendido lo anterior, el examen de Las Benévolas es complementado con obras autobiográficas como las novelas de Semprún (2013), Levi (1988; 1989), Rousset (2018) y Améry (2001), que se incorporan para recoger el testimonio de quienes experimentaron personalmente la Shoab y dejar oír la voz de los verdaderos protagonistas. En este contexto, los sobrevivientes son claves, en tanto con sus relatos dan cuenta de lo acaecido, contribuyendo a la misión de nunca olvidar. Este valioso legado permite profundizar en el sufrimiento, la comprensión, el dolor, la resistencia y la angustia. Asimismo, posibilita debatir cómo seguir viviendo, qué se hace con la memoria, cómo se convive con el Mal y cómo es posible la superación de la barbarie. Además, se considera doctrina especializada (Reyes Mate, Mellón, Löwy, Judt, Sontag, Bauman y Arendt) para realizar reflexiones que trascendiendo la experiencia personal puedan dar atisbos acerca de este régimen subrayando la necesidad de despertar la conciencia humana de un 'nosotros'.

\section{El NAZISMO}

Para examinar la cosmología nazi y comprender cómo es abordada por parte de la literatura es esencial entender el surgimiento del nazismo, liga- 
do al marco político, económico, histórico y cultural de Europa en los albores del siglo xx y, especialmente, a la ausencia de sentido de vida, al clima de decepción y malestar que abrumaba a los perdedores de la Gran Guerra. La sociedad germana se caracterizaba por su crisis de orientación y por su impresión de derrota y frustración; por eso esta ideología caló hondo en un porcentaje relevante de la población que se sentía insegura y «el fanatismo político era un refugio (y un trampolín político y social) ante la falta de certezas sobre el presente y el futuro» (Mellón, 2011: 68). La fascinación que alcanzó el nacionalsocialismo en los años treinta se explica - pues el nazismo prometía solucionar aquello-, a través de un proyecto que daba respuesta al malestar generado a raíz de la Primera Guerra Mundial, mediante una «forma política novedosa, revolucionaria, espiritual, juvenil y moderna [...] Y, a la vez, conservadora y tradicional» (Mellón, 2011: 70). Era una propuesta que embargaba a todos, en la medida que abarcaba los anhelos de la mayoría de los sectores, tanto de quienes deseaban ser parte de un proyecto hegemónico e imperial, como de quienes conscientes de la radicalidad, optaban por esta promesa colectiva, por el anhelo de pertenecer a algo relevante y transformador, «cada uno de sus miembros, si se unía al movimiento, podía convertirse en una sublime e importantísima encarnación ambulante de algo ideal» (Arendt, 2006: 363). Hitler fue exitoso porque encarnaba esta promesa de imperio, precisamente la sociedad alemana lo invistió de soberanía, pues era quien permitiría superar la incertidumbre con un proyecto de transformación que traería consigo la grandiosidad anhelada.

La doctrina política prototípica del siglo xx buscaba a través de la idea de comunidad la dominación del individualismo, así se renunciaba a las libertades, pero se era parte de un proyecto político sin igual, regenerador de la patria, que permitía sentirse parte de un todo. Por lo mismo, su nacimiento responde más a la radicalidad y la globalidad de la ideología política que a un antisemitismo de la sociedad local, ya que la conducta de los ejecutores «no procedían únicamente de un odio irracional hacia los judíos, sino ante todo de una asunción firme y razonada del recurso a la violencia para zanjar los problemas sociales más variopintos» (Littell, 2007: 676). Por tanto, «la cuestión judía no es una cuestión de humanidad, no es una cuestión de religión; es sólo una cuestión de higiene política» (Littell, 2007: 21). Si no se considera dicha vertiente y se reduce el holocausto a la problemática antisemita - como señala Aue, el oficial protagonista de Las Benévolas -, «sería olvidarse de que nuestras políticas de exterminio picaban mucho más alto» (Littell, 2007: 675), porque «el antisemitismo era ya entonces un instrumento para la liquida- 
ción no sólo de los judíos, sino también del cuerpo político del estadonación» (Arendt, 2006: 108).

Arendt (2006) advierte cómo los totalitarismos alcanzan su cometido: el primer paso para conseguir la dominación total es matar a la persona jurídica, lo que se logra colocando a ciertos individuos fuera del resguardo legal, así con la desnacionalización se obliga a la sociedad no totalitaria a reconocer su ilegalidad. Destruida la persona jurídica se asesina a la persona moral y se procede a acabar con la individualidad. Eso es lo que el nazismo hizo con los judíos: quitarle su calidad de ciudadanos, apartarlos en guetos y, posteriormente, exterminarlos. Todo se efectuó bajo un marco legal que avalaba prácticas de segregación; así se dictaron leyes que les prohibieron ejercer determinados oficios, realizar ciertas actividades y/o desplazarse por algunos lugares. Progresivamente se fue naturalizando su exclusión, se les fue apartando, individualizándolos con un distintivo que los hacía visibles, cercándolos en barrios, obligándolos a trabajar y, por último, matándolos. El exterminio respondía a la necesidad de perpetuar la raza pura que los nazis decían encarnar, por lo que no sólo se liquidó a judíos, sino a disidentes políticos, gitanos, homosexuales, rusos, polacos, inválidos, enfermos mentales, negros y todo quien se consideraba una amenaza a la 'raza aria'.

\section{EL FÜHRER COMO LA MORAL}

Ser un buen alemán quiere decir obedecer las leyes y, en consecuencia, al Führer: no puede haber nada más ético.

(Littell, 2007: 597)

El Fübrer era la referencia moral, con la cual se juzgaba la vida y la sociedad. Para el nazismo «el Volk es soberano y en el Fübrer se expresa o se encarna esa soberanía» (Littell, 2007:597). Fue tal la fuerza que cobró esta ideología, que según Mellón (2011: 71), «el nacionalsocialismo logró en Alemania entre 1933 y 1945 que sus ideas-fuerza fueran hegemónicas [...] Lo bueno, lo justo, lo ético, lo auténticamente alemán era para los alemanes de la época [...] los parámetros ideológicos establecidos por la propaganda oficial», «justo es lo que es bueno para el pueblo alemán» (Arendt, 2006: 423). Hitler constituía el imperativo categórico al cual todos debían ceñir su vida, por ende, «todas las órdenes deben ser obedecidas por muy absurdas y terribles que fueran. El ser imperialista expansión del Volk alemán todo lo justifica» (Mellón, 2011: 69). 
En una experiencia tan radical como lo fue el nazismo, el Fübrer era la ley, la verdad de una época donde «todos los componentes de la horda, se ponen al servicio del proyecto político. Sin debates ni discusiones. Teniendo fe absoluta en el Führer [...] No pueden permitirse ni vacilaciones ni dudas, ni mucho menos disidencias en el totalitario proyecto colectivo» (Mellón, 2011:70). En este régimen el individuo se disuelve en una masa homogénea y obediente que sólo debe sumisión a su líder; por ende, el verdadero triunfo del totalitarismo es justamente la transformación de la población en masa. El nacionalsocialismo alemán produjo la desaparición del 'yo' en el 'nosotros' (Todorov, 2009), así «el totalitarismo y, en consecuencia, el racismo antisemita, constituyen la tentativa, en el contexto de una sociedad en la que el individualismo está profundamente enraizado y es predominante, de supeditarlo a la primacía de la sociedad como totalidad» (Wieviorka, 1992: 81). El nazismo había triunfado convirtiendo a la población en masa inerme, había transformado a los hombres en superfluos, destruyendo la dignidad humana y el reconocimiento de los otros, es decir, había logrado matar cualquier solidaridad humana, salvo la lealtad que pudiera existir entre sus compatriotas.

En este punto no se debe olvidar que la mayoría de las restricciones que llevó a cabo el Tercer Reich eran legales, en el sentido de que se amparaban en la normativa vigente, o sea, las medidas adoptadas, aunque fuesen aberrantes, estaban consagradas jurídicamente, se enmarcaban dentro de una lógica que había penetrado aún más de lo que se quisiera aceptar. De ahí que no resulte sorprendente que, ya al final de la Segunda Guerra, los alemanes siguiesen manteniendo la fe en Hitler y en la 'Solución Final', Littell se preguntaba "¿Y qué muestra eso? Pues que diez años apenas después de la toma del poder, la mentalidad nacionalsocialista se ha convertido en la verdad de la vida cotidiana del Volk. Ha penetrado en los menores resquicios» (2007: 555). Las víctimas también se daban cuenta de ello; por ejemplo, Rousset (2018) detenido, forzado a trabajar y asistir a la aniquilación de sus compañeros, advierte cómo el fascismo cotidiano se impone en los más diversos ámbitos de la vida.

La concepción de Fübrer como la moral explica de qué manera esta ideología cobró vuelo, de modo que aunque no se estuviera de acuerdo con sus políticas, se obedecieran estrictamente, ya que constituían lo ético. Por lo mismo, «el fascismo no es simplemente una forma política, sino una tendencia más profunda que atraviesa la civilización occidental moderna» (López, 2009: 213). De esta forma, «el genocidio moderno es un proceso que las masas hacen padecer a las masas y por las masas [...] 
un proceso segmentado por las exigencias de los procedimientos industriales [...] el ejecutante está alienado respecto al producto de su acción» (Littell, 2007: 26); se trata de «máquinas obedientes, desprovistas de repugnancias morales y dispuestas a todas las ferocidades» (Todorov, 2013: 193). Precisamente, como sostiene Bauman (2006: 123), «su efectividad formidable se basaba principalmente en que su utilización estaba sujeta a consideraciones puramente técnicas y burocráticas [...] La violencia se ha convertido en una técnica $[\ldots]$ está libre de emociones y es puramente racional».

\section{EL HOLOCAUSTO: SU SINGULARIDAD Y PRODUCTO DE LA MODERNIDAD}

Reyes Mate advierte que sobre esta materia no hay consenso, en gran medida pues no es claro a lo que se hace alusión cuando se refiere a la singularidad de la Shoab; de ahí que distinga la relación con lo moral, lo histórico y lo epistémico. Mientras Reyes Mate rechaza lo primero por la imposibilidad de cuantificar el sufrimiento de las víctimas de las distintas masacres, considera que Auschwitz es singular históricamente, debido a que no solamente implicó el exterminio total de un pueblo, sino también lo hizo mediante los medios tecnológicos disponibles, con una violencia desmesurada nunca antes vista, entendiendo la matanza de los judíos como un fin en sí mismo y del cual se negó la naturaleza de crimen; así, la 'Solución Final' se alza como un hecho insólito en lo macabro y lo gratuito y por ello singular en la historia de Occidente. En similar sentido se decanta Wayne Morrison, para quien, el exterminio nazi «[f]ue único por tres razones: se llevó a cabo en el centro del mundo civilizado, se perpetró con una eficiencia técnica sólo posible en una sociedad moderna, y se ejecutó sobre la base de una voluntad genocida que había sido adoptada por el Estado moderno» (Morrison, 2012: 90). «La singularidad aterradora del sistema nazi estaba, y siempre estará, en la memoria de los sobrevivientes [...] la fría decisión, puesta en acción de manera sistemática, industrial y racional para exterminar a todo un pueblo» (Semprún y Wiesel, 2002: 27).

Reyes Mate en la comparación que realiza de este exterminio con otras masacres, reafirma su singularidad en la medida que en otros genocidios las muertes se justificaron por una determinada finalidad (compartida o no, esa es otra cuestión); en cambio allí se exterminó a judíos sistemáticamente como un fin en sí mismo, no con un objetivo estratégico, militar o geopolítico, sino con la finalidad de que debía acabarse con la totalidad de 
ese pueblo. «El exterminio como fin en sí mismo, he aquí un rasgo esencial del nacionalsocialismo» (Traverso, 2001: 146). De igual modo, para Judt (2008) la Shoab no tiene precedentes, pues «nunca antes un Estado ha decidido y anunciado, bajo la autoridad de su máximo líder, que un determinado grupo humano debería ser exterminado, a ser posible en su totalidad [...] decisión que ese Estado [...] ha aplicado con todos los medios». La eliminación de la totalidad de un pueblo por su identidad, no se había visto nunca de manera tan descarnada como se presenció en el nazismo. De ahí que Jankelevitch afirme que es:

[...] una cosa innombrable, inconfesable y aterradora, una cosa de la que retira el pensamiento y que ninguna palabra humana osa describir [...] Las orquestas tocaban a Schubert mientras que se ahorcaba a los detenidos [...] Se comercializaban los cabellos [...] Se arrancaban los dientes de oro a los cadáveres [...] esa cosa indecible que uno duda en llamar por su nombre, se dice Auschwitz. (Reyes Mate, 2003: 55)

Esto es a lo que hace referencia Arendt, que no habían comprendido en el juicio a Eichmann, pues los nazis al decretar el exterminio de los judíos estaban cometiendo un crimen contra la esencia misma del ser humano, de allí que más allá de un delito contra dicho pueblo, el holocausto constituía un crimen contra toda la humanidad, pues destruía cualquier posibilidad de solidaridad, era un delito contra la democracia y la civilización occidental, porque ponía en jaque los principios esenciales en que se sustentaba. Haciendo referencia a las dimensiones, al alcance y la singularidad de este régimen, Diner introduce el concepto de Zivilisationsbruch, que designa el rompimiento civilizatorio que se produce con la Shoah, porque al no conducir a ningún propósito ulterior, implica un quiebre con el raciocinio instrumental de Occidente (Hofman, 2011). De ahí, su singularidad.

Es vital comprender que «[e]l antisemitismo es impensable sin la Modernidad» (Reyes Mate, 2012: 70). No cabe asumirlo como producto de la barbarie, sino comprenderlo como un fenómeno de la racionalización y burocratización, como manifestación de la civilización capitalista industrial, en que la cultura de la eficiencia administrativa elimina toda interferencia ética. En otros términos, el holocausto no constituye una ruptura de la Modernidad, sino es producto de la racionalidad moderna, ya que sin el desarrollo y la utilización de la tecnología, la técnica y la ciencia no se habría podido poner en funcionamiento y dar continuidad a esta maquinaria de producción industrial de la muerte. Como reconoce Löwy (2003), si la racionalidad instrumental no es suficiente para explicar Auschwitz, es su condición esencial e indispensable en tanto «[e]n los medios de exterminio nazis, se encuentra una 
combinación de [...] la prisión descripta por Foucault, la fábrica capitalista de la cual hablaba Marx, la organización científica del trabajo de Taylor, la administración racional/burocrática según Max Weber». En este sentido, el Lager «no chocó en ningún momento con la búsqueda racional de la eficiencia, con la óptima consecución de los objetivos [...] surgió de un proceder auténticamente racional y fue generada por una burocracia fiel a su estilo y a su razón de ser» (Bauman, 2006: 39-40). Por eso, Améry (2001), seudónimo de Hans Mayer, sobreviviente del campo de exterminio Morowitz-Auschwitz, critica al desarrollo occidental porque en su máximo apogeo genera el mayor de los sufrimientos. También Rousset tras la liberación de los campos, relata su experiencia en Buchenwald en El Universo concentracionario (2018), advirtiendo hasta dónde puede ir la capacidad destructora del sistema.

Según Reyes Mate, "Auschwitz es incomprensible porque no queremos ver a la barbarie como una posibilidad latente de nuestra cultura» (2002: 5). Adelantándose a lo que iba a acontecer, Marx sostuvo que «la barbarie reaparece, pero esta vez ella es engendrada en el propio seno de la civilización y es parte integrante de ella. Es una barbarie leprosa, la barbarie como la lepra de la civilización» (Löwy, 2003). Al igual que Marx, Benjamin (2006) fue uno de los que comprendió que el avance tecnológico e industrial puede generar desastres sin precedentes ya que, aunque formalmente el progreso sea presentado como un avance en todo sentido, también puede producir las mayores masacres si se sujeta a fines malignos. El nexo entre el desarrollo de la racionalidad y la victoria de la barbarie se estableció con la instrumentalización de la razón tecnocrática a los más perversos objetivos (Hofman, 2011). La perfección en el aniquilamiento - como apuntaron Adorno y Horkheimer en la Dialéctica del Iluminismo-, se enmarca dentro de la tendencia de la racionalidad instrumental a transformarse en locura asesina. Así, en un comienzo el exterminio no fue lo suficientemente eficaz, pero se fue perfeccionando, lo que se observa en que las primeras matanzas fueron a punta de balas en campos donde los cuerpos flotaban en fosas comunes, y se acabó por utilizar hasta los dientes, los cabellos y la grasa de los cuerpos. Es paradójico debido a que, sin los avances tecnológicos alcanzados, el exterminio no habría logrado ser tan exitoso; es decir, la misma naturaleza de la civilización moderna generó este progreso regresivo o la funesta 'perfección', en términos de Reyes Mate. Por tanto, como advierte Bauman, la Shoah «demuestra que el mundo hobbesiano no ha sido completamente domeñado [...] no tenemos todavía bastante civilización [...] Si la lección de los asesinatos en masa nos enseña algo es que para prevenir semejantes problemas de barbarie se requieren todavía más esfuerzos civilizadores». (Bauman, 2006: 34) 


\section{Cuando el holocausto cobra relevancia}

La Shoab en la época de la postguerra no constituyó una preocupación relevante, una muestra de ello es que de la primera edición de Si esto es un hombre, de 2.500 ejemplares, 600 se perdieron a causa de las inundaciones que se produjeron en la bodega donde se almacenaban. Esta falta de interés también se visualizó en la prensa, que contando con información sobre lo que acontecía, la publicaron muy escuetamente o no lo hicieron. Por ejemplo, a pesar de que en 1942 The Daily Telegraph comunicó los asesinatos masivos en Auschwitz, éstos pasaron desapercibidos, ello a pesar de que:

[...] la noticia era una de las primerísimas informaciones sobre uno de los grandes hechos del siglo. Y, además, tenía la rara calidad de que podía servir para algo. La masacre estaba, entonces, sucediendo [...] saberlo podía llevar a intervenir. Pero el Telegraph la publicó, pequeña [...] y ningún otro medio la retomó. Pasarían años antes de que la humanidad decidiera horrorizarse por el Holocausto. (Caparrós, 2015)

Por ende, «si deseamos comprender el verdadero sentido del mal, hay que recordar que lo realmente horrible del exterminio de judíos no reside en que haya tenido tanta importancia, sino en que haya tenido tan poca» (Judt, 2008), es decir, el problema fue la escasa relevancia que se le otorgó. Dentro de las razones que Judt (2008) esgrime para explicar su 'invisibilidad', está la de que nadie se quería hacer cargo de lo acontecido y la mayoría hacia todo lo posible por ignorarlo, pues gran parte tuvo un rol no menor, tanto como protagonistas o cómplices. No es que no se supiera lo que estaba ocurriendo, sino más bien que no se quería conocer o asumir. Nadie lo quiso ver en su momento, siempre resultó más cómodo no darse por enterado; sin embargo, como señala Arendt (2006: 43): «la población se hallaba notablemente bien informada sobre los llamados secretos - las matanzas de judíos». De ahí que una de las víctimas de Auschwitz haya señalado que, si bien los nazis eran los culpables de esta barbarie, la sociedad también lo era por mirar impávida y no hacer nada para detener esta masacre. El remordimiento que iba a generar la internalización de este proceso como propio era lo que se buscaba evitar. Por eso el silencio se estableció como única respuesta.

Uno de los mayores miedos de las víctimas y que constituía una pesadilla recurrente en los sobrevivientes era que no les iban a creer, que ni siquiera los iban a escuchar o en el caso que los oyeran no les iban a dar importancia. Es la sensación que tuvo Francisc Boix, el exiliado catalán conocido como 'el fotógrafo de Mauthausen', al mostrar en el Juicio de 
Núremberg algunos de los negativos que logró rescatar del campo de concentración (Rubio, Colombo y Landa, 2018). Aquellas fotografías que revelaban la muerte, el hambre y el horror no querían ser miradas, a pesar de que daban cuentan de las atrocidades cometidas. Justamente porque retrataban la barbarie, no podían ni querían ser observadas al poner al descubierto el mal diabólico, ese mal que según Kant era inconcebible en el hombre (Reyes Mate, 2005). Como apunta Levi, «las víctimas y los opresores, se daban cuenta de la enormidad y, por consiguiente, de lo imposible que sería darle credibilidad, a lo que estaba sucediendo en los Lager» (1989: 12). Por eso los nazis señalaban que, aunque perdieran la batalla habían ganado la guerra ya que nadie iba a creer lo acontecido, nadie iba a querer enterarse de hasta dónde podía llegar la (in)humanidad.

\section{LA VIOLENCIA INÚTIL, LO INHUMANO Y LA ANIMALIDAD}

¡Pero esto es el infierno de Dante! (Littell, 2007: 745). Esta alusión a Dante corresponde a una frase pronunciada por un oficial nazi al visitar una fábrica de trabajo de judíos, al mirar las condiciones en que tenían que laborar y al ver los cadáveres andantes en que se habían transformado muchas de las víctimas. Mientras exclamaba esto, uno de sus acompañantes se había quedado atrás vomitando. Como cuenta Littell, el vómito era repetitivo. No sólo el protagonista tenía constantes arcadas, sino parte de los ejecutores sufría de náuseas, diarreas y malestares que se agudizaban al tener que presenciar los exterminios o participar en los mismos. Aue narra que estando en un foso debía darle el tiro de gracia a mujeres y niños que se debatían en un charco pidiendo clemencia o con los ojos perdidos; caminaba por el lodo, cubierto de sangre y cadáveres intentando no caerse, no desfallecer entre tanta muerte, entre tanta mierda. Este espectáculo del terror sin igual causaba tal estupor en los perpetradores que fue necesario recurrir a métodos más 'asépticos' mediante los que matar a otro ser humano dejase de portar una significación relevante.

La idea de burocratización de la máquina de exterminio fue central en el éxito de Auschwitz como régimen de aniquilamiento masivo: conscientes de que los individuos, por regla general, no pueden matar a otras personas sin mayores estragos, los nazis idearon un mecanismo lo suficientemente 'higiénico' para que nadie tuviera que 'ensuciarse en extremo'. De este modo, cada uno formaba parte de una gran cadena, tenía un papel importante, pero no lo suficientemente imprescindible para ser irremplazable; por eso Hoffmann (2011: 17) afirma que «dada la compleja organi- 
zación del genocidio, la imputación de culpabilidad se dificulta en sumo grado». "Las cosas se hacían solas, nadie hacía nunca nada, nadie actuaba, eran actos sin actores, algo que siempre resulta tranquilizador» (Littell, 2007: 637). La manera en que se distribuían las tareas generaba que quien firmaba las órdenes de deportación a los campos, como Eichmann, no se sintieran responsables del destino que les tenía deparado el régimen a sus víctimas pues, tal como sostienen varias declaraciones de ejecutores, ellos sólo realizaban una pequeña parte del engranaje. La maquinaria se perfeccionó hasta el punto de que al encargado de los últimos peldaños sólo le bastaba girar una llave para gasear a decenas de personas y el 'trabajo sucio' se delegaba a los propios judíos. Levi considera que "haber concebido y organizado las Escuadras ha sido el delito más demoníaco del nacionalsocialismo $[\ldots]$ se trataba de descargar [...] en las víctimas, el peso de la culpa, de manera que, para su consuelo no les quedase ni siquiera la conciencia de saberse inocentes» (1989: 47). De esta forma se liberaban de posibles responsabilidades ulteriores y preveían cualquier 'colapso'.

En referencia a la violencia desmesurada que caracterizó al nazismo, Levi sostiene que los años nazis han compartido su violencia con muchos otros, "pero se han caracterizado por una generalizada violencia inútil, que ha sido un fin en sí misma, que ha estado dirigida exclusivamente a causar dolor; a veces con un propósito determinado, pero siempre redundante, fuera de toda proporción» (1989: 91). Similar apreciación es compartida por Améry (2001) quien, en su ensayo sobre los campos de exterminio nazi, muestra cómo la violencia extrema y gratuita se constituye en el imperativo categórico del Tercer Reich. Esto se visualiza, por ejemplo, en que los deportados en cuanto llegaban a los Lager eran sometidos a un proceso de limpieza a fin de degradarlos y quitarles su identidad: les sacaban su ropa, los metían en procesos de desinfección, les cortaban los cabellos, los despojaban de cualquier posesión, de su identificación y de sus pertenencias. En este trastrocamiento general al que eran sometidos se les reducía a rutinas absurdas como hacer perfectamente la cama o la exageración desmedida de la higiene. Esta dinámica de deshumanización también comprendía el tatuaje, grabando en su antebrazo izquierdo el número en que se habían convertido. No tenía ninguna utilidad esta acción salvo la que describe Levi (1989: 102):

su significado simbólico estaba claro [...] es un signo indeleble, no saldréis nunca de aquí. Es la marca que se imprime a los esclavos y a las bestias destinadas al matadero, y es en lo que os habéis convertido. Ya no tenéis nombre: éste es vuestro nombre. La violencia del tatuaje era gratuita, era un fin en sí misma, era un mero ultraje. 
Otro suceso de violencia inútil es narrado en Las Benévolas y se produce cuando una partisana capturada es besada por oficiales alemanes y luego ahorcada. Este suceso constituye la sensación duradera del horror. Sobre el particular, Semprún se pronuncia señalando que «cabría pasarse horas testimoniando acerca del horror cotidiano sin llegar a rozar lo esencial [...] No hacen ninguna falta los campos de concentración para conocer el Mal. Pero aquí, esta experiencia habrá sido crucial, y masiva, lo habrá invadido todo». Y agrega que «el horror no se encontraba en el Mal, no era su esencia, por lo menos. No era más que el envoltorio, el aderezo, la pompa» (2013: 103).

A pesar de reconocer la violencia inútil que ejerció este régimen, los nazis no eran monstruos; para intentar explicar qué había sucedido, se habló mucho de lo inhumano, pero

$[\ldots]$ lo inhumano no existe. Sólo existe lo humano [...] y aquel Döll era un buen ejemplo ¿Qué era Döll sino un buen padre de familia que querría dar de comer a sus hijos y que obedecía a su gobierno, incluso aunque en su fuero interno no estuviera de acuerdo del todo? Si hubiera nacido en Francia o en América, habrían dicho de él que era un pilar de su comunidad y un patriota; pero nació en Alemania, así que era un criminal. (Littell, 2007:595)

Visualizarlos como engendros no permitirá examinar adecuadamente la Shoab pues, como afirma Aue:

no creo ser un demonio. Para lo que hice, siempre hubo razones, buenas o malas, no lo sé; en cualquier caso, razones humanas. Los que matan son hombres, como también lo son los muertos; eso es lo terrible [...] yo también quería vivir una vida buena y provechosa (...) Pero no se cumplió esa esperanza, y utilizaron mi sinceridad para realizar una obra que resultó ser mala y malsana, y crucé las sombrías orillas, y toda esa maldad se me metió en la vida y no existe reparación posible, y nunca la habrá. (Littell, 2007: 32)

El remordimiento asume que el padecimiento se clava en la eternidad, de ahí que no haya expiación posible, en tanto el dolor es irreparable. Así, aunque lo intentaran, el mal infligido iba permanecer en sus consciencias, no se podrían despojar de la angustia de los cuerpos, del olor dulzón de los hornos crematorios, del aroma nauseabundo de los muertos que se pegaba en la nariz y en la garganta; en fin, no eran capaces de deshacerse de tanta barbarie. Era tal la desazón que experimentaban por la violencia que ejercían que los mismos ejecutores no lograban hacerse cargo de tanta irrealidad. Aue, en el abismo de la locura, señala: «iré a buscar una supuesta sopa al supuesto comedor de oficiales y hablaremos mientras hacemos que comemos» (Littell, 2007: 386). En este punto donde todo se distorsiona, 
donde la humanidad se difumina hasta que resulta irreconocible, las cosas y los significados se trastocan, el bosque ya no es el refugio de la infancia sino el lugar donde están enterrados los cuerpos, la nieve pierde su blancura y se convierte en el frente de batalla, el olor adopta otro sentido, todo se modifica y la única pregunta que resuena en la cabeza de los perpetradores es cuánto tiempo falta para convertirse en mierda.

En este infierno indescifrable del cual Aue era parte, ya no era posible apartarse de la amargura, por lo que anuncia: «en esto me han convertido, en un hombre que no puede ver un bosque sin pensar en una fosa común $[\ldots]$ no me gusta matar [...] a veces hay que matar por deber. Pero matar por gusto es algo que se elige» (Littell, 2007: 708). Esta era la separación que hacía entre él y un maniático: Aue estaba cumpliendo su deber, si éste implicaba exterminar a un pueblo lo haría, pero ello no significaba que disfrutara matando, cruzar esa barrera significaría renunciar a cualquier posibilidad de retorno, de humanidad. Por eso, señala que «aquella decisión en las personas a cuyo cargo corría la ejecución, del peligro que corrían sus mentes, de volverse crueles e indiferentes y dejar de respetar la vida humana $[\ldots]$ yo conocía bien aquel camino atrozmente estrecho» (Littell, 2007: 683). Era un camino que Aue no quería transitar, aún no estaba lo suficientemente alienado para no conmoverse frente a la muerte de una embarazada o de un niño pequeño, aún no era un monstruo. A pesar de que estaba en el límite de no poder salir del barro, pues

asistía con regularidad a las ejecuciones; nadie me lo exigía, iba por voluntad propia $[\ldots]$ parecían haberse vuelto totalmente insensibles a su trabajo de verdugos. Yo debía ser como ellos. Tenía el presentimiento de que, al imponérseme tan lamentable espectáculo, no pretendía limar el escándalo, la sensación insoslayable de una transgresión, de una violación monstruosa del Bien y del Mal, sino que más bien sucedía que aquella sensación de escándalo se iba limando sola y era cierto que uno se acostumbraba, que, a la larga, ya no sentía casi nada; así que lo que yo intentaba recobrar desesperadamente, aunque en vano, era ese impacto inicial, esa impresión de ruptura, de una conmoción infinita. (Littell, 2007: 186)

Por lo mismo Eichmann, al igual que muchos jerarcas nazis, «no era, desde luego, el enemigo del género humano [...] no era tampoco una encarnación del mal vulgar, un robot sin alma ni rostro. Era un burócrata con mucho talento y muy competente en el desempeño de sus funciones» (Littell, 2007: 575). Esto fue lo que en síntesis sostuvo Arendt en Eichmann en Jerusalén, lo que le costó el desprecio de muchos de su comunidad, en gran parte por la incomprensión frente a su planteamiento: en vez de demonizar al nazismo, lo concibió como parte del fenómeno humano ya 
que observó que en las personas el ejercicio de la perversidad y la maldad se caracteriza más por lo rutinario y lo banal que por el sadismo y la monstruosidad. Al igual que Levi, comprendió que se piensa en sujetos «sádicos, marcados por un vicio de origen. Y, en lugar de ello, estaban hechos de nuestra misma pasta, eran seres humanos medios, medianamente inteligentes, medianamente malvados: salvo excepciones, no eran monstruos, tenían nuestros mismos rostros, pero habían sido mal educados» (1989: 175). Sin embargo, es mejor creer que lo acontecido es producto de unos cuantos trastornados, no se quiere asumir que

Las SS de los Lagers eran más bien animales obtusos que demonios sutiles. Habían sido educados en la violencia: la violencia corría también por sus venas [...] Se desbordaba de sus rostros, de sus gestos, de su lenguaje. Humillar, hacer sufrir al enemigo era su oficio de cada día; no pensaban en ello, no tenían segundos fines [...] No quiero decir que estuviesen hechos de una sustancia humana perversa, distinta de la nuestra [...] sencillamente habían estado sometidos durante algunos años a una escuela donde la moral corriente había sido subvertida (Levi, 1989: 105).

Nos sorprende la alienación a la cual una ideología radical puede someter a los individuos, nos deja perplejos de qué manera tan drástica puede convertirse a las personas en meros artefactos ejecutores sustraídas de cualquier ética. Sin embargo, estos entes en que se transformaban los individuos tienen un límite que se vislumbra en que «por muy embrutecidos y muy acostumbrados que estuvieran, ninguno de nuestros hombres podía matar a una mujer judía sin acordarse de su mujer, de su hermana o de su madre, no podía matar a un niño judío sin ver ante sí, en la fosa, a sus propios hijos. Aquellas reacciones suyas, aquella violencia, aquel alcoholismo, aquellas depresiones nerviosas, aquellos suicidios, mi propia tristeza, todo demostraba que el otro existe, que existe como otro, como humano, y que no hay voluntad ni ideología ni cúmulo de necedad y alcohol que puedan cortar ese vínculo, tenue pero indestructible» (Littell, 2007: 155).

Una muestra de esta posibilidad de escapar de la indolencia aconteció cuando los escuadrones especiales encontraron una joven que sale ilesa de la cámara de gas, tal como lo describe Levi (1989):

Los hombres estaban perplejos, la muerte era su trabajo cotidiano, la muerte era una costumbre, porque precisamente o se enloquece uno el primer día o se acostumbra, pero aquella mujer estaba viva [...] estos esclavos embrutecidos por el alcohol y por la matanza cotidiana se han transformado; delante de sí no tienen ya a una masa anónima, el río de gente espantada, atónita [...] lo que hay es una persona. 
A pesar de que estaban configurados para el exterminio, reconocer a esa mujer les permitió darle identidad, reconocerse en ella, esconderla para que pudiera sobrevivir, a pesar de que estaban diariamente conviviendo con la muerte, participando de ésta. Es la misma lógica que ocurre con Ana Frank: con su muerte el mundo se conmueve, tal vez mucho más que con el exterminio de millones de personas, pues a través de su diario de vida es posible identificarse, sentirse parte de su historia. Por eso, Todorov (2009: 176) subraya que «mientras más lejanas y extrañas sean sus víctimas, mejor será: se las extermina sin remordimientos, equiparándolas más o menos con los animales».

Littell narra a través de Aue historias en las cuales aún es posible desligarse de esta barbarie y reconocer al Otro, como el caso de una embarazada que fue fusilada por error. Previendo que el nacimiento venía en camino, un nazi efectuó el parto, pero en cuanto uno de los oficiales se dio cuenta, azotó la cabeza del bebé, dándole muerte. Similar crudeza se puede ver en el caso del niño judío que era protegido por los nazis porque tocaba el piano magistralmente; cuando debido a un accidente este niño perdió la movilidad de una de sus manos, fue llevado a los campos de concentración. De ahí que Aue advierte que puede acontecer que «los hombres que al principio pegan por obligación acaban por cogerle el gusto» (Littell, 2007: 629). En ello residiría la distinción entre monstruos y ejecutantes: en no caer en la tentación de encontrar placer en el dolor ajeno.

Analizando la relación de lo inhumano y la animalidad con las víctimas, Levi (1989: 96) considera que «todavía no somos animales, no lo seremos mientras tratemos de resistir»; en este marco narra que en su tren rumbo al campo de concentración improvisaron un retrete con una manta para defecar y cuenta cómo con ese pequeño trozo de tela y dos palos renunciaban a convertirse en animales. Por regla general, los viajes duraban muchas horas o días y no contaban con agua, comida ni un orinal. Estas precarias condiciones tenían por objeto denigrar al máximo a los deportados para que llegaran a los campos exhaustos, sin posibilidad alguna de oponer resistencia. En este contexto de horror, la posibilidad de rebelarse, de huir, de escapar era en la mayoría de los casos impensable. Por eso, Littell describe que:

[...] lo que al guardia le parece insoportable es esa resistencia, esa persistencia callada del otro, $y$, en consecuencia, el guardia le da una paliza para intentar que desaparezca esa humanidad común. Por supuesto, no funciona: cuanto más pega el guardia, más se da cuenta de que el preso se niega a considerarse a sí mismo como no humano. Al final no le queda ya más solución que matarlo, lo cual es admitir el fracaso de forma definitiva (Littel, 2007: 630). 
En este contexto, el lenguaje se hace fundamental para denostar al otro, para quitarle su humanidad, su esencia. Para los nazis, los judíos no eran personas sino animales y esto explica que emplearan con ellos los mismos términos. Por ejemplo, cuando les arrojaban la comida, pronunciaban la palabra utilizada para dar de comer a los animales; el que tuvieran que alimentarse en el suelo sin cubiertos, no se debía a que los campos carecieran de ellos, sino que el hecho de comer en el suelo y con las manos tenía un significado simbólico relevante que se resumía en que los judíos se alimentaban desesperadamente de cualquier cosa que se les arrojara, tal y como hacían los puercos. También el lenguaje cobraba relevancia en la posibilidad de subsistir. Varios testimonios hacen alusión a lo que implicaba no poder entender las órdenes dadas, el estar impedidos de seguir la dinámica del campo; tanto Levi como Semprún concuerdan que si bien el azar jugaba un gran rol en salir con vida de un campo, el saber alemán constituía una herramienta esencial para que esta posibilidad se concretara.

Si bien hubo resistencia en los campos, fue escasa y drásticamente silenciada por los nazis, que eran conscientes de que su conocimiento sólo serviría para incentivar futuras rebeliones. Una de las rebeliones más conocidas fue el alzamiento del gueto de Varsovia en 1943. El novelista estadounidense de origen polaco León Uris, en su Mila 18 (1961) narra cómo los polacos hicieron frente a la maquinaria fascista durante más de un mes. Este gueto se constituyó en un símbolo fundamental en la medida que demostraba que era posible sublevarse frente a la barbarie; protagonizó una hazaña que demostró que la lucha encarnizada era un acto simbólico de gran valor, que dejaba claro que a pesar de las humillaciones con que vejaban constantemente a sus víctimas, los perpetradores no lograban quebrar su voluntad, su esperanza y su capacidad de resistir. Un episodio similar lo constituyó la rebelión que la Escuadra Especial organizó en octubre de 1944 en Auschwitz; en esa ocasión los Sonderkommandos hicieron volar uno de los hornos crematorios y se enfrentaron a las SS. Si bien dicho acto fue aplacado a las pocas horas, su importancia radica en ser una de las pocas tentativas de rebelión de la historia de los lagers. A pesar de que nadie haya sobrevivido, sirvió para demostrar que, si bien les habían quitado todo, aún conservaban la capacidad para resistir. Asimismo, la oración de los muertos que cantaba uno de los sobrevivientes de Buchenwald en yiddish durante su agonía, es una imagen que narra Semprún (2013) para contar cómo la lucha persistía aún en el momento final.

Los campos de exterminio, como su nombre indica, eran lugares de aniquilamiento, de muerte de miles de personas y por eso el ánimo mayo- 
ritario en su población era de desolación. Como apunta Levi, ellos no pensaban en rebelarse, ese ímpetu correspondía a quienes conservaban la posibilidad de pensar en un futuro. Ellos sólo procuraban sobrevivir, ya que

Habíamos estado viviendo durante meses y años de aquella manera animal, no por propia voluntad [...] por el hambre, el cansancio, el miedo y el frío, y el espacio de reflexión, de raciocinio, de sentimientos, había sido anulado. Habíamos soportado la suciedad, la promiscuidad y la desposesión sufriendo mucho menos de lo que habríamos sufrido en una situación normal, porque nuestro parámetro moral había cambiado [...] Nos habíamos olvidado no sólo de nuestro país y de nuestra cultura sino también de nuestra familia, del pasado, del futuro que habíamos esperado, porque como los animales, estábamos reducidos al momento presente. (Levi, 1989: 65)

En igual sentido, Améry (2001), describiendo cómo se sufre la violencia en los campos y la condición inhumana en que quedaban las víctimas, afirma que el prisionero del Lager es un 'ya muerto', no hay más deber para él que morir, ser el producto final de la industria del Mal. Por eso en el campo el pensamiento era infructuoso y perjudicial, convocaba a la autodestrucción en tanto en que en Auschwitz «el hombre espiritual se encontraba aislado, abandonado completamente a sí mismo» (Améry, 2001: 60). También Rousset, al exponer cómo este régimen creó cosmos de destrucción de la humanidad, definió el universo de los campos de concentración como un espacio que se cierra sobre sí mismo, un no-lugar donde se expresa la descomposición de la sociedad y se normalizan las prácticas de exterminio, de modo que la muerte habita entre los deportados: «hombres sin convicciones, famélicos y violentos: hombres portadores de creencias destruidas, de dignidades menospreciadas; todo un pueblo desnudo, interiormente desnudo, despojado de toda cultura, de toda civilización [...] un pueblo destruido por los golpes». Y añade que «[e]n una hora tragicómica el hombre ha perdido su piel. Diligentes funcionarios han descuartizado fuera de orden y medida su ser concentracionario» (Rousset, 2018: 12-14). Por eso Améry (2001: 193) señala que «no me angustia ni el ser ni la nada ni dios ni la ausencia de dios, sólo la sociedad: pues ella, y solo ella, me ha infringido el desequilibrio existencial al que intento oponer un porte erguido».

Cabe preguntarse si en este contexto existía la posibilidad de fraternidad, pues las acciones de resistencia en gran medida quedaban condicionadas a encontrar en el Otro a un camarada, en confiar a ciegas, en asumir que no te delatarían a pesar del hambre, del frío y del agotamiento. Ese vínculo, Semprún lo encontró en Alberto, su compañero. Por ello, citando a Malraux, Semprún (2013: 66) afirma que busca «la región crucial del alma donde el 
Mal absoluto se opone a la fraternidad». Los sobrevivientes no coinciden en qué medida esta posibilidad de fraternidad se dio en los campos. Por ejemplo, Levi hace hincapié en que gran parte del drama del campo lo constituían las relaciones que se daban entre los internos, que se resumían en competición y rivalidad pura. Por ende, en vez de la camaradería que uno esperaría, reinaba un odio, una necesidad de imponerse sobre los demás, de modo que el lager se resumía en «la guerra permanente de todos contra todos» (Littell, 2007: 814). Por su parte, Semprún (2013: 30) apela a esta fraternidad como modo de subsistir a tanta barbarie y señala que «la muerte, un mendrugo de pan, una especie de fraternidad. Nos concernía a todos, era la sustancia de nuestras relaciones. No éramos otra cosa más que eso». En lo que hay consenso es que los campos de concentración eran un fiel reflejo de la vida. En este sentido Kertéz (2002: 137) señala: "Auschwitz, dije a mi mujer, me pareció más tarde una mera exacerbación de las mismas virtudes para las cuales me educaron desde la infancia». Igualmente, Littell (2007: 628) reflexiona: «¿el propio campo, toda aquella organización rígida, aquella violencia absurda, aquella jerarquía meticulosa, no sería acaso sino una metáfora, una reductio ad absurdum de la vida cotidiana?»

\section{DESPUÉS DEL hOlOCAUSTO ¿ES POSIBLE SUPERAR EL HORROR?}

Las víctimas de la Shoab comparten la angustia, la muerte, el miedo, la desesperanza y el sinsentido. Por ejemplo, Jean Améry en Más allá de la culpa y la expiación. Tentativas de superación de una víctima de la violencia, publicado en 1966, más que una mirada sobre el Mal, ofrece un relato sobre el dolor, pues en el Lager no había mundo posible. Améry, nacido en Austria, con el Tercer Reich se sintió extranjero en su propia patria; y su lengua materna al ser la utilizada en los Lagers, se convirtió en un veneno para el alma. Lo mismo le pasó a Paul Celán, pues el idioma enseñado por su madre, con el que escribió palabras excelsas, fue el que se empleó para exterminar masivamente. Por eso, Elie Wiesel en su discurso en el $50^{\circ}$ aniversario de conmemoración la liberación manifestó que «después de Auschwitz, la condición humana ya no es la misma. Después de Auschwitz, nada volverá a ser lo mismo».

Los sobrevivientes coinciden en la necesidad recurrente de superar lo vivido, de allí que muchos de los relatos necesitan ser contados, mientras otros no pueden ser narrados. Es lo que les sucedió a Primo Levi y a Semprún, respectivamente. La quiebra que se produce es tan radical, que la 
masacre permanece ahí, en el cotidiano, en sus sueños, en el intento de construir una nueva vida. En esta tentativa de superar el infierno por el que han transitado, muchos se preguntan cómo seguir viviendo. Nietzsche dijo que sin olvidar no hay manera de vivir. Es complejo determinar cómo abordar esta experiencia. Varios supervivientes se lo han planteado y no pocos se han decantado por no seguir viviendo. Resulta difícil continuar luego de una experiencia tan radical. Semprún reflexionó sobre cómo hacerse cargo, sobre si es posible mirar la vida, no sólo como una pausa, sino liberándose realmente de lo vivido. Para Semprún lo externo al lager era sólo un receso, ya que lo que constituía la realidad era el campo de concentración; de ahí que en sus pesadillas recurrentemente escuchase el grito: ¡hornos crematorios apaguen! Por ello afirma que, al regresar, tuvo que optar por seguir viviendo o escribir su experiencia. Era tanta la angustia que experimentaba, que él mismo se preguntaba cómo otros podían y necesitaban contar todo lo ocurrido; mientras a él recordar lo desgarraba, a Levi lo liberaba hasta un punto que no resulta del todo evidente, pues después de casi cuarenta años Levi terminó suicidándose, al igual que lo hicieron Paul Celán y Améry. Hay sobrevivientes que dedicaron gran parte de su vida a narrar sus experiencias. En ese intento por reconstruir sus vidas, dar testimonio no sólo constituye un ejercicio personal de vital valor para que nunca más vuelva a ocurrir un exterminio masivo, sino implica un espacio de diálogo, de comunicación con las futuras generaciones que, al no haber vivir el genocidio nazi, no cuentan con dicha vivencia. De este modo, el relato se transforma en un espacio colectivo, pero a la par genera angustia, tal como manifiesta Kértez (2002: 104): «Descubrí que no escribo para buscar la alegría, sino todo lo contrario, que por medio de la escritura busco el dolor, el dolor más intenso, casi insoportable, seguramente porque la verdad es dolor».

También el miedo de perder la memoria se hace presente en los supervivientes. Por ejemplo, Wiesel, apelando a la fragilidad de la memoria, se cuestiona cómo contar todo lo que hay que contar, entendiendo que "guardar silencio está prohibido, pero hablar es imposible» (Semprún y Wiesel, 2002: 30). Entonces, junto a Semprún, conversa cómo poder dar testimonio y seguir viviendo, ya que el escribir sobre el Lager revive no sólo la memoria, sino también la angustia: «Cuanto más escribo, la memoria se vuelve insistente, pero naturalmente, la angustia también regresa» (2002: 32). La experiencia post-concentraria es vivida de diversas formas por los sobrevivientes. Mientras Améry considera al resentimiento como una legítima reacción frente al holocausto, negándose a la idea de otorgar sentido al sufrimiento, otros testimonios como el de Levi reivindican la necesidad de perdonar. 
Verdugos y sobrevivientes recuerdan lo acontecido. Significó un antes y un después en sus vidas, que no todos logran superar, como plasma Semprún al afirmar que:

no parece que me encuentre más allá de tanta muerte [...] He comprendido de repente que tenían razón esos militares para asustarse, para evitar mi mirada. Pues me había realmente sobrevivido a la muerte, no la había evitado. No me había librado de ella. La había recorrido, más bien, de una punta a otra. (Semprún, 2013: 27)

Lo que les aterraba a los soldados que liberaron Buchenwald era la mirada de Semprún, pues todo lo demás - el hambre, la ropa, el olor, la suciedad - era compartido por los demás sobrevivientes, era un constante en el campo. Lo que le aterró a Semprún fue la mirada que le devolvían, pues pensaba que debía ser algo muy dramático lo que reflejaban sus ojos para que los soldados lo observaran de ese modo. Testimonios de sobrevivientes señalan que al liberarse los campos, la gente se alejaba de ellos, eran una vergüenza, resultaban incómodos; como atestiguó Wiesel, «nos habíamos acercado al abismo, al abismo de la humanidad. Les mostramos lo que un ser humano es capaz de hacer. Estos fueron los límites extremos. Nadie quería enfrentarse a eso». (Semprún y Wiesel, 2020: 28). Era tal el aniquilamiento que habían perpetrado los nazis sobre sus víctimas, que en el momento de liberación varios supervivientes relatan que se quedaron perplejos, mudos, sin tener consciencia de lo que acontecía, pues ya estaban muertos o, como manifiesta Wiesel, «fuimos incapaces de experimentar alegría. Todavía estábamos en las garras de la muerte» (Semprún y Wiesel, 2002: 44). Por eso, como sostuvo Kertész «nadie se recupera jamás de la enfermedad que es Auschwitz» (2002: 96); queda una desconfianza duradera e inamovible, pues a pesar de la liberación, «los alemanes podían volver en cualquier momento, es decir, que aun así no vivía del todo» (Kertész, 2002: 72-73). De este modo, se produce lo que Améry denomina la deslocalización del judío, en tanto dejaba de tener patria en el mundo de los vivos. Por eso, para Améry (2001) desde Auschwitz ser judío significa acometer al mundo sin la confianza de recibir nada de él y vagar en busca de un lugar del que no hay noticia.

La experiencia resulta tan dramática que hace que el campo de concentración se vislumbre como lo real, frente a la vida: «Primo Levi formulaba esta angustia que compartíamos con una concisión inigualable. Nada era verdad sino el campo, eso es. Lo demás, la familia, la naturaleza en flor, el hogar, tan sólo eran breve vacación, ilusión de los sentidos» (Semprún, 2013: 261). En otros términos, «quien ha sido torturado lo sigue estando 
[...] Quien ha sufrido el tormento no podrá ya encontrar lugar en el mundo, la maldición de la impotencia no se extingue jamás. La fe en la humanidad, tambaleante ya con la primera bofetada, demolida por la tortura luego, no se recupera jamás» (Levi, 1989: 22). En similar sentido, Améry (2001: 83) asevera que «[1]a tortura es el acontecimiento más atroz que un ser humano puede conservar en su interior», porque destruye la posibilidad de ser hombre y proyectar un mundo. Por ello, a pesar de lo que se pudiera creer, la liberación de los campos no trajo consigo inmediatamente la felicidad, sino como narra Levi:

En la mayoría de los casos, la hora de la liberación no ha sido alegre ni despreocupada: estallaba sobre un fondo trágico de destrucción, matanza y sufrimiento. En aquel momento, en que sentíamos que nos convertíamos en hombres, es decir, en seres responsables, volvían los sufrimientos de los hombres: el sufrimiento de la familia dispersa o perdida, del dolor universal que había a nuestro alrededor; de la propia extenuación, que parecía que no podría curarse, que era definitiva; de la vida que había que empezar de nuevo en medio de las matanzas. (Levi 1989: 61)

\section{LA RESPONSABILIDAD}

Se acabaron los pájaros [...] el humo del crematorio los ha ahuyentado, [no, es] el olor a carne quemada. (Semprún, 2013: 17)

Los pájaros a los que hace mención Semprún eran lo que había desaparecido del cielo. Ni las aves querían oler la carne chamuscada de los cuerpos. Mientras el humo de los hornos seguía subiendo, los alemanes y el mundo entero no quería enterarse del holocausto. No es que los campos estuvieran a kilómetros de distancia de las ciudades, sino más bien más cerca de lo que cualquiera quisiera reconocer; por ejemplo, en Dachau, en varios segmentos, sólo una reja separaba el campo del poblado.

La responsabilidad constituye uno de los temas más complejos cuando se examina la 'Solución Final' pues, como asevera Levi, «el vencedor es dueño también de la verdad, puede manipularla como quiere, ya se justificarían las fosas comunes de alguna manera» (1989: 13). Lo relevante no es cuántas personas murieron, sino cuántos inocentes - 'nuestros' inocentes - murieron; y tendrán esta calidad únicamente cuando les sea otorgada: «lo que importa precisamente es quién muere y a manos de quién [...] la identidad lo es todo» (Sontag, 2003: 12). Tendrán esa calidad únicamente cuando 'nosotros' se la otorguemos. Por lo mismo, Littell (2007: 674) subraya que «la hierba crece muy espesa encima de las tumbas de los ven- 
cidos y nadie le pide cuentas al vencedor». Sobre el particular, Antonio Madrid manifiesta que:

el dolor de las personas ha sido utilizado como instrumento de control político e ideológico sobre la población. No en vano Reyes Mate, siguiendo a Benjamin, dice: El recuerdo de las víctimas es capaz de cuestionar la victoria eterna de los vencedores, es capaz de exorcizar los gérmenes letales del presente, siempre dispuestos a repetir la historia y es capaz de neutralizar la parte asesina que llevamos dentro [...] La única pregunta relevante es: ¿queremos hacer nuestra la causa de los vencidos, o queremos seguir con la nuestra, hecha sobre los intereses de los vencedores? (Madrid, 2002: 218)

De ahí que resulte tan compleja la tarea de juzgar, pues en la determinación de inocentes y culpables, no se puede olvidar que se está delineando la verdad desde el prisma de los vencedores. Al final si se analiza las acciones de uno u otro bando se percatará, como afirma Aue, que constituiría «un error grave desde mi punto de vista pensar que el sentido ético de las potencias occidentales difiere tan de raíz del nuestro [...] una potencia es una potencia y no se hace potencia, tampoco lo sigue siendo por casualidad» (Littell, 2007: 675). En este sentido, Aue continúa argumentando que

no nos diferenciamos de los bolcheviques más que por nuestras respectivas valoraciones de las categorías de problemas por resolver: basaban ellos su enfoque en un cuadro que se leía horizontalmente (las clases) y nosotros el nuestro en vertical (las razas); pero ambos eran deterministas por igual y llegaban a conclusiones similares respecto al veneno que aplicar. (Littell, 2007: 676)

Semprún apunta a que la elección de ser víctima o verdugo no dependía de su voluntad, sino más bien era una cuestión del azar: Por ello plantea que «tal vez aquel joven soldado no tuviera nada que reprocharse, salvo el haber nacido alemán en la época de Adolf Hitler [...] Inocente no sólo de haber nacido alemán [...] de encarnar involuntariamente la fuerza brutal del fascismo» (2013: 46). En este mismo sentido se decanta Aue al señalar que «quien desee emitir el juicio de que las acciones alemanas durante aquella guerra fueron criminales, es a toda Alemania a quien hay que pedir cuentas [...] Sólo el azar lo convierte en asesino en vez de héroe o muerto» (Littell, 2007: 598). Por ello, para Sichère «no hay hombres buenos y hombres malos, verdugos de nacimiento y víctimas predestinadas, sino que cada hombre lleva en sí mismo lo peor como una posibilidad atroz» (cit. en Montes, 2013: 88).

Más allá de las responsabilidades individuales de los perpetradores, Newman y Erber (2002: 6) intentan comprender el genocidio y, considerando a Arendt, al experimento de Milgram de los perpetradores de la Shoah, a las estructuras del funcionamiento nazi, a la centralidad del anti- 
semitismo, a los procesos políticos, al personal burocrático y al marco ideológico, plantean que el holocausto «fue un evento creado por el hombre, el resultado de creencias y comportamientos humanos [por eso] Las contribuciones de la psicología social que nos ayudan a comprender cómo se forman las creencias humanas y cómo se forma el comportamiento no debiesen ignorarse». Al confrontar este exterminio, estos autores plantean que enfrentarlo siempre será una experiencia aterradora y desorientadora, siendo «tarea de los científicos sociales intentar dar sentido a esta forma extrema de comportamiento humano colectivo» (2002: 325).

Precisamente, se han desarrollado diversas teorías sobre la responsabilidad que le cabe a la población alemana: desde aquellas que plantean que los civiles eran completamente inocentes, a aquellas que consideran que la sociedad germana fue tan culpable como los propios ejecutores. Las teorías contemporáneas más aceptadas sostienen que la población local no podía no saber lo que estaba aconteciendo y que, por tanto, al 'voltear la cara y mirar hacia el lado', tenían una cuota no menor de responsabilidad, ya que, como subraya Sontag, "a partir de determinada edad nadie tiene derecho a semejante ingenuidad y superficialidad, a este grado de ignorancia o amnesia» (2003: 133). Justificar su inacción en no saber qué estaba pasando, es un argumento que cada día más cae por su propio peso, pues «¿sería posible que no lo supiera? Las chimeneas de Birkenau soltaban humo a diario [...] Pero, bien pensando, si no quería saber tenía la oportunidad de no saber, las normas del secreto y del camuflaje también valían para eso» (Littell, 2007: 623). Como sostiene Levi «responsables, en grado menor o mayor, fueron todos, pero que detrás de su responsabilidad está la de la gran mayoría de los alemanes, que al principio aceptaron, por pereza mental, por cálculo miope, por estupidez, por orgullo nacional [...] a Hitler, lo siguieron mientras la fortuna y la falta de escrúpulos lo favoreció» (Levi, 1989: 176).

Al respecto cabe plantearse ¿la sociedad tenía alguna otra posibilidad de actuar distinto? Es complicado analizarlo desde un hoy despojado del miedo, también porque ese juicio implica juzgarlos desde la mirada de los vencedores; en este punto no es posible olvidar que las denominadas democracias europeas no pararon la barbarie hasta que ésta cobró proporciones inmensas. Por lo mismo, varios autores arguyen que si la política de exterminio no hubiera superado las fronteras de Alemania, no se hubiera frenado. Esto hace que Améry (2001), después de padecer Auschwitz, clame por no olvidar, porque el resentimiento no sólo deba ser contra Alemania como colectivo, sino contra Europa, por el silencio otorgante frente a 
los indicios de antisemitismo extremo y, a diferencia de Levi, apele por el no olvido, por negar el perdón y porque al verdugo no se le amortigüe la presencia de su acto. En este contexto, plantea que el resentimiento es un ejercicio de honestidad moral y de higiene espiritual, la única tentación contra la tentación del olvido, del eterno retorno; Auschwitz es imperdonable y por ello «todo perdón y olvido forzados mediante presión social son inmorales» (Améry, 2001: 153).

Entonces ¿qué hacer con los que actuaron? Ya no pueden esgrimir que no sabían lo que conllevaba el nazismo. Si bien en un comienzo este régimen utilizó un lenguaje abstracto para enmascarar sus objetivos, luego los hizo patente, tal y como se percibió en el discurso pronunciado en octubre de 1943, conocido en los Juicios de Núremberg, en el cual se llamaba al exterminio por su nombre, diciendo expresamente que las matanzas eran de hombres, mujeres y niños. Es decir, la barbarie se mostraba 'sin máscaras', nadie podía argüir que no estaba enterado de lo que significaba la denominada 'Solución Final'. Ello «resultaba tan incómodo, aquella ausencia total, por una vez, de ambigüedad y era como si estuviera violando una regla no escrita, más imperativa [...] la regla del tacto [...] el Fübrer lo había querido así, y de ahí la angustia que sentían» (Littell, 2007: 671), ya que nadie podría justificarse en la ignorancia. Por consiguiente ¿cómo se construye?, ¿a partir de qué se avanza?, ¿cómo se continúa? Como denuncia Arendt (2014), en Alemania después de la caída de Hitler la mayoría de los nazis siguieron estando en el poder. Según Levi, si se hubiera hecho una des-nazificación más exigente habríamos tenido que deshacernos de una generación completa de alemanes. Y, al parecer, nadie estuvo dispuesto a ello.

\section{Conclusión}

A modo de cierre es esencial reflexionar sobre la memoria y su rol en la Shoah. Adorno sostenía que "pensar que después de esta guerra la vida podrá continuar normalmente, aún que la cultura podrá ser restaurada - como si la restauración no fuera ya su negación - es idiota [...] Si la situación continúa imparable (continuísmo), la catástrofe será perpetua» (Reyes Mate, 2002:8). Por eso para poder superar tanta barbarie hay que hacerse cargo de los muertos, de las acciones y omisiones, de la responsabilidad. A pesar de que la historia ha demostrado que los genocidios vuelven una y otra vez, es fundamental el analizar el por qué, el conocer su surgimiento y mantención. La memoria debe estar presente para estar alerta frente a la barbarie; es un aviso de lo que somos capaces de hacer, de allí 
que «no condolerse $[\ldots]$ ésas serían las reacciones de un monstruo $[\ldots]$ no somos monstruos [...] Nuestro fallo es [...] de empatía: no hemos sido capaces de tener presente esta realidad» (Sontag, 2003: 16).

La construcción de la memoria es un ejercicio vital, en tanto recuerdo del pasado, actitud ética para vivir el presente y enseñanza para la actualidad (Forero, Rivera y Silveira, 2012), para que no se olvide lo acontecido, para que nunca más vuelva a ocurrir. Si bien recordar no nos asegura que no se vuelva a repetir, ya que no existen certezas de que la masacre vuelva, recordar es vital, pues como sostiene Sontag «recordar es una acción ética, tiene un valor ético en y por sí mismo [...] la insensibilidad y la amnesia parecen ir juntas» (2003: 134). Así que, si bien la mención de un infierno «nada nos dice [...] sobre cómo sacar a la gente de ese infierno, cómo mitigar sus llamas. Con todo, parece un bien en sí mismo reconocer, haber ampliado nuestra noción de cuánto sufrimiento a causa de la perversidad humana hay» (Sontag, 2003: 133). De ahí que la tarea de la memoria resida en esta función de no hacernos olvidar hasta dónde somos capaces de llegar. Lo anterior, en palabras de Reyes Mate (2002: 12), se resume en que puede que lo verdaderamente universal sea la «tendencia permanente de la condición humana al horror y que el papel de Auschwitz sea el de mostrar puesto que se produce en el seno de una civilización altamente desarrollada - hasta dónde puede llegar y cómo puede llegar a ser». Por lo mismo, Levi (1988: 208) afirma que «no podemos comprenderlo; pero podemos y debemos comprender dónde nace, y estar en guardia. Si comprender es imposible, conocer es necesario, porque lo sucedido puede volver a suceder, las conciencias pueden ser seducidas y obnubiladas de nuevo: las nuestras también». En el mismo sentido, «los judíos cultivan - legítimamente- su propia memoria [...] el judeocidio [...] no sólo les concierne a ellos: la humanidad entera, al tomarlo a su cargo, transforma a los millones de víctimas de los nazis en una muralla contra la repetición del horror» (Judt 2008).

El triunfo de la memoria está dado por regresar a lo humano, por recuperar la identidad que la maquinaria nazi había borrado, por recordar el nombre que los detenidos tenían antes de ser encerrados en los campos, como atestigua Elie Wiesel: "[1]o había olvidado todo incluso mi nombre. Al final de mi tiempo en Auschwitz [...] Tenía mi número A7713. Eso fue todo. Yo era un número. Y de vez en cuando alguien de mi pueblo simplemente recuerda que tenía un nombre» (Semprún \& Wiesel, 2002: 33). Por lo mismo, Wiesel coincide con Semprún (2002) en la necesidad de dar testimonio de lo ocurrido, de que los sobrevivientes hablen de lo experimentado en los campos, para que no vuelva a acontecer. 
El desafío de la memoria es evitar la repetición de atrocidades y en ésta, como plantea Semprún, se encuentra presente el 'rito pedagógico de dar testimonio', de relatar lo acontecido a todos quienes no lo hayan experimentado, a las generaciones jóvenes que están ávidas por conocer lo sucedido, por saber sobre la Shoab y los mecanismos totalitarios que llevaron al exterminio de millones de personas. Si bien con la muerte de los sobrevivientes «ya no habría una memoria inmediata de Buchenwald: ya nadie sería capaz de decir, con palabras surgidas de la memoria carnal [...] lo que habrán sido el hambre, el sueño, la angustia, la presencia cegadora del Mal absoluto» (Semprún, 2013: 312), debería ser posible reconocerse en el otro. Ahí radica el papel de la memoria, en la necesidad de que a pesar de que mueran los sobrevivientes su dolor permanecerá latente. Por eso, si bien iniciativas como las de Levi y Bruck de dar charlas en las escuelas en los años setenta y ochenta, no podrán replicarse a futuro, pues la primera generación de sobrevivientes está muriendo, es posible implementar otros proyectos para que el holocausto no caiga en el olvido, como la integración de los relatos de supervivientes en el currículo escolar, para que las generaciones venideras se concienticen sobre el Tercer Reich; o registrar los testimonios de víctimas en medios audiovisuales y ponerlos a disposición del público masivo en plataformas digitales y en espacios del recuerdo o museos, como se puede visualizar en la exposición online Las últimas cartas del holocausto. Cartas contra el olvido. La posibilidad de identificarse y representarse el exterminio nazi, a pesar de no haberlo experimentado, es posible. Lo relevante es dejar registro de las narraciones de los supervivientes para que no desaparezcan. De este modo, frente a las interrogantes de Aarons (2006): ¿dónde está el 'lugar' del holocausto en la actualidad? y ¿quiénes son los custodios de la memoria?, cabe argüir que a pesar de la pérdida irrecuperable del testimonio directo, para que las historias no se pierdan y darle voz a quienes ya no pueden contar lo acaecido, la tarea de las generaciones contemporáneas es recuperar esas experiencias y transmitirlas, a las generaciones futuras.

La historia se repite y la desmemoria está más presente en el cotidiano de lo que se cree. Lo más fácil sería culpar a unos cuantos sujetos. Pero esa respuesta implica no asumir que no fuimos capaces de hacerle frente, esa respuesta remite a reflexionar sobre nuestra responsabilidad como sociedad en la continuación de la barbarie. La producción industrial de muerte se logró porque política e históricamente había existido una preparación de 'cadáveres vivientes'. Por eso es necesario estar alerta frente a ideologías que desprecian al otro, frente a regímenes que justifican separaciones en virtud de una supuesta incompatibilidad, frente a la naturalización de la exclusión y frente 
al peligro de utilizar el temor como pretexto para justificar restricciones a los derechos fundamentales. Ya no cabe excusarse en la ignorancia o en la ingenuidad. Es hora de aprender de la historia, poner la ética en el centro y entender que la dignidad humana debe ser el principio rector. Es una tarea compleja, pero constituye un desafío al cual no se debe renunciar como sociedad, porque lo que está en juego es la construcción de una democracia coherente. En esta lucha, la función de la memoria es esencial, en la medida que posibilita un no-olvido, un nunca más a la barbarie. Por ello Semprún insiste en que la conmemoración del holocausto no se instaura como un mero sitial del recuerdo, sino como un acto político, como «memoria de los valores democráticos fundamentales, que son valores de tolerancia, una negación al olvido» (Semprún \& Wiesel, 2002: 42).

\section{REFERENCIAS}

Aarons, Victoria (2016), The third generation Holocaust narratives. London, Lexington books.

Améry, Jean (2001), Más allá de la culpa y la expiación. Valencia, Pretextos.

Arendt, Hannah (2006), Los orígenes del totalitarismo. Madrid, Alianza.

Arendt, Hannah (2014), Eichmann en Jerusalén. Barcelona, De Bolsillo.

Argullol, Rafael (2006), «El fascismo de la posesión inmediata», El País (Opinión), 14 de febrero. https://elpais.com/diario/2006/02/14/opinion/1139871607_850215.html

Bauman, Zygmunt (2006), Modernidad y holocausto. Madrid, Sequitur.

Benjamin, Walter (2006), Sobre el concepto de historia. Madrid, Abada.

Caparrós, Martín (2015), «El peor silencio», El País semanal, 10 de marzo. https://elpais.com/elpais/2015/03/09/eps/1425913290_289843.html

Forero, Alejandro; Iñaki Rivera y Héctor Silveira. (Eds.) (2012), Filosofía del mal $y$ memoria. Barcelona, Anthropos.

Hoffmann, Michael (2011), Historia de la literatura de la Shoah. Barcelona, Anthropos.

Judt, Tony (2008), «Demasiado Holocausto mata al Holocausto», Le Monde Diplomatique en español, 154: 12-13.

Kertész, Imre (2002), Kaddish por el hijo no nacido. Barcelona, Acantilado.

Levi, Primo (1988), Si esto es un hombre. Buenos Aires, Proyectos editoriales.

Levi, Primo (1989), Los hundidos y los salvados. Barcelona, Muchnik Editores.

LitTell, Jonathan (2007), Las Benévolas. Barcelona, RBA Libros. 
LóPEZ-VicuÑA, Ignacio (2009), «Malestar en la literatura: escritura y barbarie en Estrella distante y Nocturno de Chile de Roberto Bolaño», Revista chilena de literatura, 75: 199-215.

Löwy, Michael (2003), «La dialéctica de civilización: barbarie y modernidad en el siglo xx», Herramienta, 22; 141-150. (Publicado originalmente en 2002 en la revista online Memoria)

Madrid, Antonio. (2002), «La cultura contemporánea del sufrimiento», El Vuelo de Icaro, 2-3: 217-236.

Mellón, Joan (2011), «Las Benévolas de J. Littell. La cosmovisión nacionalsocialista», Claves de razón práctica, 213: 68-72.

Montes, Cristian (2013), «La seducción del mal en Estrella distante de Roberto Bolaño», Mitologías hoy, 7: 85-99.

Morrison, Wayne (2012), Criminología, civilización y nuevo orden mundial. Barcelona, Anthropos.

Newman, Leonard y Ralph Erber (2002), Understanding Genocide: The Social Psychology of the Holocaust. New York, Oxford University Press.

Reyes Mate, Manuel (2002), «La singularidad del holocausto». Ponencia presentada al seminario La filosofía después del holocausto II. Madrid, Instituto de Filosofía.

Reyes Mate, Manuel (2003), Por los campos de exterminio. Barcelona, Anthropos.

Reyes Mate, Manuel (2005), «El Holocausto: singularidad y memoria». Conferencia pronunciada por Reyes Mate y Sultana Wahnón (5/5/05).

Reyes Mate, Manuel (2012) «La teoría Crítica: La escuela de Frankfurt. Walter Benjamin: Tesis sobre el concepto de historia». En A. Forero, I. Rivera y H. Silveira, eds., Filosofía del mal y memoria. Barcelona, Anthropos: 61-91.

Rousset, David (2018), El Universo concentracionario. Barcelona, Anthropos.

Rubio, Salva, Pedro Colombo y A. Landa (2018), El fotógrafo de Mauthausen. Barcelona, Norma.

Semprún, Jorge (2013), La escritura o la vida. Barcelona, Tusquets.

Semprún, Jorge y Elie Wiesel (2002), It is impossible to remain silent. Reflections on fate and memory in Buchenwald. Indiana, Indiana University Press Stable.

Sontag, Susan (2003), Ante el dolor de los demás. Madrid, Alfaguara.

Todorov, Tzvetan (2013), Nosotros y los otros. Madrid, Biblioteca Nueva.

Todorov, Tzvetan (2009), La conquista de América. Buenos Aires, Siglo xxi.

Traverso, Enzo (2001), El totalitarismo. Buenos Aires, Eudeba.

Wieviorka, Michel (1992), El espacio del racismo. Barcelona, Paidós. 